\title{
Análise Textual Discursiva no estudo da palavra Experiência nas dissertações de mestrado em Educação em Ciências
}

\author{
Lais Francielle Costa da Rosa (lais.pitrez@yahoo.com) \\ Universidade Federal do Rio Grande FURG \\ Aline Machado Dorneles (lidorneles26@gmail.com) \\ Universidade Federal do Rio Grande FURG
}

\begin{abstract}
Resumo: O presente artigo visa compreender o sentido da palavra Experiência nas pesquisas a nível de mestrado na área de Educação em Ciências. Centrou-se na análise das dissertações publicadas no Banco de Teses e Dissertações da CAPES (Coordenação de Aperfeiçoamento de Pessoal de Nível Superior). A partir das dissertações coletadas como dados de pesquisa, a análise foi realizada no viés da Análise Textual Discursiva (ATD), sendo realizado o processo de unitarização e categorização dos resumos de cada pesquisa, emergindo a composição de três metatextos como modo de comunicar as categorias finais emergentes. Apresentam-se as compreensões relacionadas a pesquisa em Educação em Ciências a partir da experiência, os significados construídos na perspectiva da experiência e as relações entre pesquisador e os sujeitos colaboradores. Argumenta-se a importância de um olhar atento ao movimento de pesquisar a partir da experiência, pois permite perceber o lugar do outro e também as relações estabelecidas com a pesquisa.
\end{abstract}

Palavras-chave: Sentido da experiência; Experiência do pesquisador; Vivências na pesquisa.

Resumen: Este artículo tiene como objetivo comprender el significado de la palabra Experiencia en la investigación a nivel de maestría en el área de Educación Científica. Se enfocó en el análisis de las disertaciones publicadas en el Banco de Tesis y Disertaciones CAPES (Coordinación para el Perfeccionamiento del Personal de Educación Superior). A partir de las disertaciones recogidas como datos de investigación, se realizó el análisis en el sesgo del Análisis del Discurso Textual (DTA), y se llevó a cabo el proceso de unificación y categorización de los resúmenes de cada investigación, con la composición de tres metatexto como una forma de comunicar las categorías emergentes finales. Se presentan los entendimientos relacionados con la investigación en Educación Científica desde la experiencia, los significados construidos desde la perspectiva de la experiencia y las relaciones entre investigador y sujetos colaboradores. Se argumenta la importancia de una mirada atenta al movimiento de investigar desde la experiencia, ya que permite percibir el lugar del otro y también las relaciones que se establecen con la investigación.

Palabras clave: Sentido de la experiencia; Experiencia del investigador; Experiencias en investigación. 


\section{INTRODUÇÃO}

A palavra experiência remete a significados diferentes a cada pessoa que vive o momento de experienciar. Tendo esta concepção em vista, o objetivo do presente artigo é compreender o sentido da palavra experiência nas pesquisas em educação em ciências.

A naturalização das palavras torna-se um movimento presente na vida tanto em âmbito profissional ou pessoal, como também a repetição de palavras, sem talvez construir sentidos sobre como cada palavra determina nosso pensar. A repetição de certas palavras leva-nos a saber sua historicidade e significado das mesmas. Larrosa (2002) tem a convicção de que as palavras têm poder e força, assim produzem sentidos, criam realidades e tem a ver como nos colocamos diante de nós mesmos, dos outros e do mundo, assim relacionando a palavra com o pensamento:

As palavras determinam nosso pensamento porque não pensamos com pensamentos, mas com palavras, não pensamos a partir de uma suposta genialidade ou inteligência, mas a partir de nossas palavras. E pensar não é somente "raciocinar" ou "calcular" ou "argumentar", como nos tem sido ensinado algumas vezes, mas é sobretudo dar sentido ao que somos e ao que nos acontece. E isto, o sentido ou sem-sentido, é algo que tem a ver com as palavras (Larrosa, 2002, p. 21).

Com base no autor, o estudo da palavra nos remete a pensar e buscar o significado e o sentido das palavras trazidas, muitas vezes, de modo repetitivo na pesquisa. Gadamer (1997) diz que a palavra é entendida imediatamente a partir do nome e nomeia a "coisa" de uma maneira muito mais íntima e com significado. Sendo assim, quando não tem significado algum, a palavra não difere quanto ao som e também não remete à "coisa".

Obviamente que também pode ocorrer que não se chame a alguém pelo seu nome correto, porque pode ser que o tenhamos confundido com outro, ou que não se empregue a "palavra correta" para uma coisa, porque esta não é conhecida. Mas então o que é incorreto não é a palavra, mas o seu emprego. Só aparentemente se refere à coisa para a qual é empregada. Na realidade ela é a palavra adequada para outra coisa diferente, e para esta, sim, é correta (Gadamer,1997, p.597).

O uso das palavras, por Gadamer, é um instrumento de diferenciação das coisas, existindo uma historicidade de cada palavra. Sendo assim, cada palavra tem uma origem e um significado para determinada coisa, determinado por sua etimologia 
Etimologia é a parte da gramática que trata da origem e da formação das palavras.

Partindo de um estudo etimológico da palavra experiência, compreendemos que sua história na linguagem é construída pelos diferentes significados existentes ao longo dos anos. Assim Amatuzzi (2007) traz que:

[...] o termo experiência, pela sua origem, significado o que foi retirado (ex) de uma prova ou provação (-perientia); um conhecimento adquirido no mundo da empiria, isto é, em contato sensorial com a realidade. Experiência relaciona-se com o que se vê, com o que se toca ou sente, mais do que com o pensamento. $[\ldots]$ (p.2).

Amatuzzi (2007), ao afirmar que experiência se relaciona com o que se vê, com o que se toca ou sente, dialoga com Larrosa (2002) que diz que: a experiência é o que nos passa, o que nos acontece, ou que nos toca.

Desse modo, o presente artigo tem como objetivo compreender o sentido da palavra Experiência nas pesquisas de mestrado em Educação em Ciências. Assim, realizamos um estudo bibliográfico na área como modo de compor sentidos e significados relacionados à palavra experiência nas dissertações disponíveis e selecionadas para a pesquisa no banco de teses e dissertações da CAPES ${ }^{1}$. Nesse banco, estão publicadas as dissertações e teses defendidas nos programas de pós-graduação do Brasil.

A partir da pergunta de pesquisa de cunho fenomenológico: o que é isso que se mostra da experiência na pesquisa em Educação e Ciências? Visamos descrever os movimentos da pesquisa na perspectiva do estudo da palavra e assim perceber as vivências, as marcas e sentidos trazidos ao aplicar o termo experiência no ato de pesquisar.

Apresentamos, a seguir, um caminho metodológico centralizado na Análise Textual Discursiva como possibilidade de construir compreensões sobre o fenômeno investigado. Do processo de busca das dissertações no Banco da CAPES, na

${ }^{1} \mathrm{O}$ nome CAPES refere-se à coordenação de aperfeiçoamento de pessoal de nível superior, fundado pelo MEC, Ministério da Educação. Cada registro de tese ou dissertação contém informações básicas relacionadas com o nome do aluno, título, resumo, palavras-chave, instituição acadêmica, etc. Todas estas informações são fornecidas à CAPES pelo curso de pós-graduação e dão acesso a qualquer pessoa, sendo ela ou não da área acadêmica.

Link de acesso: http://catalogodeteses.capes.gov.br/catalogo-teses/\#!/ 
unitarização e categorização dos resumos que traziam a palavra experiência, e a construção de três metatextos como modo de comunicar as categorias finais, sendo esses: Pesquisa na Educação em Ciências a Partir da Experiência, Significados Construídos a Partir da Experiência e A Experiência nas Relações entre o Pesquisador e os Sujeitos Colaboradores.

Assim, o estudo bibliográfico é realizado a partir dos pressupostos da fenomenologia e da hermenêutica, favorecendo a construção de compreensões sobre a experiência e os sentidos dessa palavra trazidos nas pesquisas na área da Educação em Ciências.

\section{METODOLOGIA}

O estudo bibliográfico foi realizado no Banco de Teses e Dissertações da CAPES, com a utilização da palavra experiência(s) como descritor principal.

Decidimos centrar a busca na área de Ciências: nesse movimento, é notável a fragilidade do sistema de busca do site da CAPES pela quantidade de filtros semelhantes, sem uma diferenciação entre as linhas de pesquisa e descrição das áreas. Obtivemos um total de 809 dissertações, como mostramos no quadro abaixo:

Quadro 1 - Filtros utilizados no Banco da Capes.

\begin{tabular}{|c|c|c|c|}
\hline Tipo & Área do Conhecimento & Área de Concentraçāo & Total de Resultados \\
\hline Dissertaçāo & Ensino de Ciénciss e Matemática & $x \times x$ & 603 \\
\hline Dissertaçāo & Ensino de CiËnciss e Matemática & Eduaçōo em Clënciass & 39 \\
\hline Dissertaçāo & Ensino de Ciänciss = Matemática & Ensino de Ciänciss & 8 \\
\hline Dissertaçāo & Ensino & Eduạ̧a em Ciénciss & 39 \\
\hline Dissertaçāo & Eduaçāo & Educạ̄o nas Clënciss & 45 \\
\hline Dissertaçāo & $x 00$ & Educsçäo em Clënciss e Educaçäoem Quimics & 75 \\
\hline \multicolumn{4}{|c|}{ Soma d o 5 Result ad o5 $=809$} \\
\hline
\end{tabular}

Fonte: as autoras.

Diante do número tão elevado para uma análise qualitativa, refinamos as dissertações selecionadas e buscamos aquelas em que o descritor principal, experiência(s), aparecia no título e no resumo da dissertação. Assim, a presente busca oportunizou chegar a um total de dezenove (19) dissertações.

Chegamos ao nosso corpus de análise da pesquisa e questionamentos emergiram no processo, tais como: Qual é o sentido da palavra experiência na pesquisa em 
educação em Ciências? O que é isso que se mostra da palavra experiência na pesquisa em Educação e Ciências? A partir da ATD, foi construído um movimento hermenêutico e fenomenológico de pesquisa, visando interpretar o que está posto e compreender o fenômeno que se mostra.

\begin{abstract}
A fenomenologia proclama o retorno às coisas mesmas, salienta o estudo dos fenômenos na forma como se manifestam ao sujeito, enfatizando a experiência original, o mundo vivido. Por isso ela, necessariamente, precisa valer-se da linguagem, posto que é por seu intermediário que o sentido surge e se manifesta (Moraes e Galiazzi, 2015, p.28).
\end{abstract}

Dessa forma, iniciamos o processo de análise por meio da Análise Textual Discursiva (ATD) de Moraes e Galiazzi (2016), considerando as etapas a seguir.

Primeiramente, após uma leitura atenta dos resumos de cada dissertação, recortamos fragmentos retirados dos resumos denominados como Unidade de Significado por Moraes e Galiazzi (2016) que dizem que nesse primeiro movimento: “A construção das unidades de significado representa um movimento e interpretação dos textos, uma leitura rigorosa e aprofundada" (p.71). Esse processo requer um olhar atento e interpretativo do pesquisador, no qual sua interpretação vai além do objetivo da pesquisa e isso se mostra pela compreensão de cada unidade de significado. O grande desafio dessa etapa é fragmentar o resumo e perceber os sentidos construídos para a palavra experiência, sendo esse o fenômeno em estudo, permitindo novos olhares sobre o todo: pesquisador, sujeitos, pesquisa e mundo.

Após essa desordem que a ATD nos permite ao recortar fragmentos dos resumos, seguimos para nosso próximo movimento dentro da análise, denominado categorização. Nele, encontramos relações entre os fragmentos e buscamos categorias que permitissem identificar essa junção de unidades significado. Nesse movimento, o pesquisador começa a perceber o que se mostra para além de sua intencionalidade de pesquisa e se envolver nos caminhos que ela percorre. É preciso interpretar e compreender a "voz" do sujeito, mesmo que o rumo da pesquisa desvie o questionamento, e isso se dá pela impregnação e envolvimento do pesquisador na análise. Gadamer (2015, apud Simplicio e Galiazzi, 2019) diz que: interpretamos o que o autor quis dizer no seu texto e não o que ele quis dizer com seu texto, pois quando buscamos essa compreensão, não conseguimos suspender nossos preconceitos e vivências e isso afeta nossa interpretação. 
A ATD dialoga com a ideia de interpretação supracitada e tem por intenção a compreensão e a reconstrução de conhecimentos existentes do sujeito e do pesquisador, os quais não conseguem suspender e negar suas experiências de mundo. Nesse momento, é preciso afastar-se de seus "pré-conceitos", suas "compreensões prévias", suas "verdades" e se abrir para deixar que o fenômeno se mostre na pesquisa, etapa de compreensão. Etapa desafiadora pelo valor nas vozes dos sujeitos, como podemos perceber na citação abaixo:

\begin{abstract}
A Análise Textual Discursiva tem como fundamento hermenêutico a valorização dos sujeitos e seus modos de expressão a partir do exame interno dos fenômenos. Para isto, é necessário, na (re)construção teórica de significados, considerar a diversidade dos sujeitos da pesquisa que estão articulados em redes coletivas de significados sobre as quais o pesquisador é desafiado a compreender, a descrever e a interpretar. A hermenêutica ajuda a entendermos esta (re)construção, em que a interpretação é como uma "imitação" do leitor-pesquisador que busca sentidos do autor do texto ao carregar seus próprios. Isto exige autoria nas interpretações do pesquisador no estudo do fenômeno (Sousa, 2016, p.31).
\end{abstract}

Ao iniciar essa etapa, o pesquisador, na preocupação de compreender que fenômeno se mostra, aprende pelos sentidos.: sentidos estes, percebidos nos movimentos de interpretação das "escritas", "falas", dos sujeitos, que são expressos e notados em cada leitura e (re)leitura. A ATD convoca o pesquisador para um viés de análise participativo, no qual, a cada passo dado, acontece uma transformação pessoal, formativa, que busca interpretar o que está escrito e se desafia a um distanciar-se entre suas vivências e a do outro. Assim, o pesquisador se mostra ao buscar compreender algo que não compreendia, como uma fusão de horizontes que menciona Moraes e Galiazzi (2016), "o que a palavra diz e o que o conceito diz".

Em nossa análise, cento e duas (102) unidades significado (US) foram construídas dos resumos durante a leitura, frente à pergunta de pesquisa: o que é isso que se mostra da palavra experiência na pesquisa em Educação e Ciências? Cada unidade recebeu um código com o número da unidade, a autoria de cada dissertação e o ano de publicação. As unidades são uma (re)interpretação do pesquisador no seu movimento de leitura e como afirmam os autores, o número de unidades reflete as compreensões do pesquisador.

De algum modo o limite dos recortes é dado pela capacidade das unidades ainda expressarem sentidos significativos para a pesquisa. Não cabe proceder a recortes em que as unidades já não expressam relações significativas. Num 
extremo, com unidades excessivamente pequenas, perde-se a conexão com o fenômeno. No outro, unidades excessivamente amplas deixam de destacar elementos de significado particulares, ao mesmo tempo em que o processo analítico é dificultado (Moraes e Galiazzi, 2016, p.88).

Assim, foi estabelecida uma relação entre algumas unidades durante esse movimento na qual onze (11) categorias, denominadas iniciais, expressam o processo de interpretação do pesquisador. Novas compreensões dos fenômenos são reveladas na categorização das unidades em que o movimento exige um envolvimento e um constante retorno às informações compreendidas pelo pesquisador, partindo de seu objetivo na pesquisa, como podemos observar na citação de Moraes e Galiazzi (2015):

\begin{abstract}
A construção de categorias prepara descrições e interpretações que se baseiam na estrutura das categorias, encaminhando-se assim os resultados de uma investigação. No seu conjunto representam sínteses elaboradas pelo pesquisador no sentido de expressar as novas compreensões atingidas em relação ao seu objetivo de pesquisa (p.111).
\end{abstract}

Desse processo de categorização inicial, reorganizamos e aproximamos categorias semelhantes e obtivemos, a partir de onze (11) categorias iniciais, três (3) categorias finais, sendo essas: a) Pesquisa na Educação em Ciências a partir da Experiência, b) Significados construídos a partir da Experiência e c) A Experiência nas relações entre o pesquisador e os sujeitos colaboradores.

Seguindo adiante, após as categorias finais serem delimitadas e contemplarem as unidades significado diferentes e próximas, o movimento de autoria e personalidade do pesquisador acontece na apresentação de metatextos, em que as interpretações e compreensões, juntamente com os teóricos, dialogam com o pesquisador, apresentando seus olhares e percepções durante o caminhar da análise.

Assim, partimos para o próximo movimento, denominado metatextos pela ATD: movimento de escrita com reencontro as unidades que compõe as categorias para dialogar com as compreensões e interpretações construídas sobre o fenômeno investigado. Assim, para Moraes e Galiazzi (2015), a descrição das unidades dá sentido e significado à análise e a construção dos metatextos se faz no próximo movimento em que os textos produzidos devem expressar mais do que a compreensão pessoal do pesquisador, ou seja, precisam descrever explicações e compreensões dos participantes, ainda que reconstruídas pelo pesquisador. Por isso, a produção escrita ocorre num processo nominado em espiral, afirma Moraes e Galiazzi (2015), no qual o texto nunca 
Edição Especial: I SSAPEC - Simpósio Sul-Americano de Pesquisa em Ensino de Ciências

ISSN: 2595- $4520 \quad$ Vol. 4, n. 3. 2021

está inteiramente concluído e que a cada retomada, novos sentidos e compreensões são feitas e interpretadas pelo pesquisador.

Nesse ir e vir nas unidades, juntamente com suas categorias, o pesquisador descreve suas compreensões e interpretações do que os sujeitos dizem e mostram em suas escritas, sendo em nosso estudo os resumos. Assim, a seguir, as categorias finais da análise trazem em sua descrição as interpretações e compreensões do movimento de pesquisa.

\section{SENTIDOS E SIGNIFICADOS DA EXPERIÊNCIA NA PESQUISA}

Essas categorias apresentadas como finais na análise possibilitam dialogar com as compreensões e interpretações do pesquisador em sua pesquisa, tendo como intenção perceber que sentido a experiência na pesquisa em Educação é trazido pelos pesquisadores. Como diz Larrosa (2011) sobre o uso e abuso da palavra experiência em educação, o uso sem pensar acaba banalizando a palavra sem ter consciência plena de suas enormes possibilidades teóricas, críticas e práticas. As diferentes experiências apresentadas nas dissertações são percebidas pelo pesquisador no caminhar da análise, assim a busca por compreender o fenômeno experiência acontece como objetivo geral na pesquisa. As interpretações que o pesquisador compreende ao adentrar os resumos dá voz e espaço para a experiência da pesquisa dos sujeitos.

\subsection{PESQUiSA NA EDUCAÇÃo EM CIÊNCIAS A PARTIR DA EXPERIÊNCIA}

O uso da palavra experiência é praticado e usado nos diferentes campos da Ciência. Para as Ciências Naturais, muitas vezes, refere-se ao experimento, como exemplo mistura de água e óleo, e o uso da palavra tem como sentido representar um método científico. Mas, ao relacionar a palavra experiência no campo da pesquisa em Educação em Ciências, surgi os seguintes questionamentos que sentido os pesquisadores da área da Educação trazem à palavra experiência? Que lugar é esse de pesquisa? Existe relação com a experiência? Para isso, remetemos ao conceito de experiência trazido abaixo: 
Benjamin (1994) aponta que a experiência é a fonte onde os narradores bebem. Experiências que vão se constituindo tanto no conhecimento tecido ao longo de anos de permanência em certo lugar, como naqueles tecidos no caminhar pelo mundo. Narrar é a possibilidade de compartilhar essas experiências. (Ribeiro, Souza e Sampaio, 2018, p.132)

Dialogando com a citação, notamos que a experiência não deve ser um conceito genérico, precisamos poder individualizá-la por intermédio de situações e de percursos sinalizados pelo pesquisador. Assim, buscamos compreender essa experiência sinalizada nos resumos das dissertações analisadas.

Compreendemos a palavra experiência com sentidos outros, quando a mesma proporciona uma vivência sinalizada tanto pelos sujeitos como pelo próprio pesquisador.

No presente estudo, a busca é pela experiência que se mostra ao pesquisador durante a análise e sua individualidade, partindo da vivência dos sujeitos e/ou pesquisador. Para isso, Larrosa (2011, p.7) cada um vive a sua experiência de um modo único, singular, particular e próprio, apesar de muitas vezes ser o mesmo acontecimento.

Nos fragmentos dos resumos das dissertações, há o entendimento da experiência como individual de cada pesquisa, com exercício de perceber a alteridade dos sujeitos da pesquisa e do pesquisador em compreendê-la.

Esta pesquisa buscou entender as experiências de leituras cotidianas de jovens estudantes concluintes do ensino médio, residentes no Noroeste do Rio Grande do Sul. Os jovens pesquisados foram estudantes no Câmpus Santo Augusto do Instituto Federal Farroupilha no ano 2012 (US5. Samborski, 2013).

Com a finalidade de investigar como a recuperação das memórias de visitantes ao museu de ciências pode contribuir para a compreensão de uma experiência museal, esta pesquisa foi desenvolvida, sob forma de um estudo de caso com participantes de uma experiência ocorrida no espaço de um museu de ciências no ano de 2009. Tal experiência teve por objetivo proporcionar uma vivência de vinte quatro horas no ambiente do museu, aproveitando o intercâmbio de conhecimentos científicos, tecnológicos e culturais (US14. Souza, 2015).

As unidades mostram as experiências vividas e o fenômeno de ambas é perceber o pesquisador e os sujeitos na pesquisa a partir da experiência. Na primeira unidade, a experiência é a leitura cotidiana com jovens, na segunda, as memórias recorrentes à visita museal. Temos, portanto, diferentes experiências que mostram a individualidade de cada pesquisador e sujeitos envolvidos. 
Sendo a experiência o interesse principal da pesquisa Cladinin e Connelly (2015, p.30), fortemente influenciados por Jonh Dewey, dizem que o termo experiência se transforma de um termo comum na linguagem de educadores, para um termo de pesquisa e, assim, nos permite criar caminhos para compreender os cotidianos profissionais e formativos no campo da Educação. Sendo assim, o pesquisador que busca compreender como que a experiência é vivida pelos sujeitos se torna um participante ativo, que se envolve e vive junto, na maioria das pesquisas, de seus sujeitos/colaboradores.

Moraes e Galiazzi (2016) afirmam que o movimento do pesquisador é um exercício de mergulho num discurso do outro, em que busca "compreender e interpretar" o que o outro disse. E nesse movimento o pesquisador também está vivenciando uma experiência, qual seja a experiência que deseja investigar (Clandinin e Connelly, 2015, p. 120).

Buscando compreender a experiência, Larrosa (2011, p.7) diz que:

[...] a experiência é sempre subjetiva, contudo, essa subjetividade se trata de um sujeito que é capaz de deixar que algo lhe passe, quer dizer, que algo passe a suas palavras, a suas ideias, a seus sentimentos, a suas representações, etc. Trata-se, portanto, de um sujeito aberto, sensível, vulnerável exposto.

Essa subjetividade é diferente de sujeito para sujeito visto que, apesar de viver a mesma experiência, torna-se individual pelo seu caminhar durante a mesma. $\mathrm{O}$ fragmento de análise a seguir mostra uma pesquisa voltada aos saberes e culturas das crianças, e, a partir de suas vozes, favorece a construção do ensino de ciências partindo de suas experiências.

Nosso objetivo é analisar como as vozes das crianças e suas culturas revelam suas participações nas experiências e saberes sobre ciências, no espaço da Escola e no Bosque da Ciência. Desta feita, pretendeu-se partilhar reflexões sobre as crianças em seu imaginário e na relação com seus pares, bem como, ressaltar algumas concepções de infância, tendo em vista suas interações na Escola como ambiente pedagógico e no espaço não formal ouvindo suas vozes e observando suas reações (US19. Mululo, 2017).

A experiência que se busca aqui pretende trazer para a pesquisa o imprevisível e incontrolável, sendo perceptíveis tais aspectos no excerto, pois remete à pesquisa no cotidiano escolar com as crianças promovendo espaços de reflexão e de viver o imaginário no ensino de Ciências. 
Clandinin e Connelly (2015, p.165) afirmam que os interesses de pesquisa provêm de nossas próprias histórias, assim, em alguns resumos, é perceptível esse lugar do pesquisador. Na unidade abaixo, o mesmo se mostra em sua pesquisa ao trazer a cartografia, que é um método que parte da experiência do sujeito.

Elege a cartografia como metodologia de pesquisa, pois permite um acompanhamento de processos, composições, produções marcadas pelos encontros. Uma configuração cartográfica a partir dos processos de formação da pesquisadora e a escritura-vida dos trajetos de formação do professor quilombola Ilton Gonçalves, em Guaraqueçaba, estado do Paraná. Um encontro a partir da leitura do livro autobiográfico "Minha Triste e Alegre História de Vida"; e a produção de depoimentos do professor e autor do livro, a propósito de sua trajetória de formação e da construção de suas práticas pedagógicas (US10. Pereira, 2015).

Nesse resumo, o pesquisador se mostra ao buscar compreender a sua própria experiência. A cartografia conversa com a ideia da experiência formadora ou transformadora quando vivida intensamente pelo sujeito. Toda pesquisa opera em campos de territórios diferentes, e nesses territórios encontramos o pesquisador. Nessa metodologia, a intenção é pesquisar o "entre": entre o pesquisador e o território de pesquisa. Percebemos que o território de pesquisa do pesquisador é sua formação para além da docência a qual, a partir da leitura de um livro, elabora relação com suas vivências, na experiência durante sua formação. $O$ pesquisador se desafia a pesquisar sobre sua formação docente e isso ele mostra na escrita de seu resumo. Assim, o intuito desta dissertação é pesquisar a própria experiência de formação, outro lugar de experiência em que se percebe o pesquisador.

Ao perceber o lugar da experiência, o movimento de pesquisa torna-se diferente, o pesquisador vive a experiência e também faz parte dela (Clandinin e Connelly, 2015, p.120), sendo outra maneira de se perceber nos caminhos da investigação, como no excerto abaixo:

Portanto, adoto a pesquisa qualitativa em um processo de pesquisa-ação pela qual ao formá-la me formo, ao fazê-los refletir também reflito, ao fazêlos significar (res)significo. Este processo de investigação se deu no Clube de Ciências da UFPA (CCIUFPA), um espaço não formal de ensino com perfil de "laboratório pedagógico". Foi neste laboratório pedagógico que testei hipóteses, experimentei experiências e assumi papéis de pesquisadora, orientadora, professora e cientista em um movimento de (res)significação de experiências por meio de outras novas experiências (US8. Cajueiro, 2017). 
A metodologia da pesquisa-ação trazida na unidade acima é uma forma de investigação baseada em uma (auto)reflexão de si e no coletivo, assim oportunizando os processos de (re)significar sua própria prática. Para dialogar com essa definição, Gullich (2012) que diz em sua tese que:

\begin{abstract}
Abordagens e discussões teoricamente fundamentadas permitem-me afirmar proposições no sentido de avançar e alargar o conceito de investigação-ação justamente pela compreensão em profundidade do referencial da teoria educacional crítica e das percepções de mudança nos conhecimentos, que fui apreendendo nas vivências junto à realidade investigada. Este alargamento do conceito possibilita pensar na direção de um processo de investigaçãoformação-ação. Uma vez que, para além de sobre, é também para a formação que a investigação-ação se configura e se torna efetiva, com sentido transformador das concepções e das práticas pedagógicas, dos currículos, dos contextos escolares, quiçá das práticas sociais (p.197).
\end{abstract}

A relação da citação com a unidade e a interpretação do pesquisador mostram que o potencial de uma investigação-ação está para além da formação do outro. Nesse processo, há a transformação para o pesquisador que vive a experiência ao mesmo tempo em que incentiva o processo de reflexão-ação acerca da experiência vivenciada pelos sujeitos. O pesquisador, no movimento de perceber tais compreensões dos sujeitos se forma, reflete, e (re)significa a experiência vivida, ou seja, reconhece o papel da reflexão investigando sua própria ação-prática de ensino.

Percebemos o quanto a experiência tem um potencial formador e transformador para os sujeitos colaboradores da pesquisa e para o próprio pesquisador, o quanto ela, ao ser vivenciada pelo ser humano, é um meio de formação pessoal, profissional e humano independentemente do lugar em que ocorra. Assim diz Larrosa (2011, p.8), o sujeito da experiência é como um território de passagem, como uma superfície de sensibilidade em que algo passa e que isso que me passa, ao passar por mim ou em mim, deixa um vestígio, uma marca, um rastro, uma ferida".

\begin{abstract}
O pesquisador é uma das vozes interpretativas nas redes coletivas de diálogo acerca do fenômeno. Seu papel é o que Gadamer (2015) exemplifica na atuação do intérprete de uma língua estrangeira. O pesquisador precisa traduzir para si e para outros o que o texto diz. Nesta tradução, ele coloca um pouco de si, suas vivências, seu contexto interpretativo (Sousa, 2016, p.35).
\end{abstract}

A pesquisa na área da educação em ciências a partir da experiência tem uma ampla abordagem teórica e metodológica, como apontamos nessa categoria. 
Edição Especial: I SSAPEC - Simpósio Sul-Americano de Pesquisa em Ensino de Ciências

ISSN: 2595- $4520 \quad$ Vol. 4, n. 3. 2021

Percebemos a diversidade nos campos de pesquisa e a relação dos pesquisadores com as experiências dos sujeitos colaboradores da investigação.

Por fim, a intenção dessa categoria foi compreender o pesquisador, os sujeitos, e o lugar da pesquisa a partir da experiência apresentada em cada resumo. A importância de o pesquisador buscar compreender como a experiência foi vivida pelos sujeitos e também por ele próprio, está no entregar-se ao processo de fazer pesquisa, pois o pesquisador muito diz sobre si ao fazer uma pesquisa nesse campo. Assim, a pesquisa a partir da experiência é um convite para construir relações do pesquisador com o lugar, com suas próprias histórias na investigação e com os sujeitos colaboradores.

\subsection{SIGNIFICADOS CONSTRUÍDOS A PARTIR DA EXPERIÊNCIA}

O pesquisador busca, na teoria, compreensões a partir da sua experiência na pesquisa: desta forma ele reflete, repensa e reconstrói significados. As primeiras relações dialógicas com a fundamentação teórica são sinalizadas nos resumos das dissertações analisadas. O diálogo com teóricos surge para conversar com a teoria da experiência, sendo assim a unidade abaixo mostra o pesquisador fundamentando suas compreensões e interpretações da pesquisa.

A necessidade e a busca por teóricos foram surgindo e se tornando mais conectadas à pesquisa realizada, sob a forma de uma curiosidade epistemológica (FREIRE,1996); à medida que a pesquisa progredia, novas questões surgiam e orientavam a escrita e as leituras (US2. Calixto, 2013).

Percebemos o movimento de construção do conhecimento em que há uma intenção de diálogo e cujo encontro teórico acontece no caminhar da experiência da pesquisa. O pesquisador da dissertação acima compreende que o movimento da experiência permeia a pesquisa e suas compreensões e diálogos cuja teoria segue o caminhar desse movimento. Como diz Paulo Freire (1996) o conhecimento é continuamente criado e recriado tal como pessoas refletem e agem no mundo. Assim, acontece quando há a construção de significados a partir da experiência, com as compreensões do pesquisador que durante a investigação se abre aos caminhos da pesquisa que pode ir se desvelando, buscando na experiência os caminhos a compreender. 
Guedes e Ribeiro, no livro Pesquisa, alteridade e experiência, dialogam com o pesquisador quando dizem que: "a experiência da pesquisa também tem a ver com o acontecer, a travessia, a transformação" (2019, p.27). Poderemos perceber, na unidade a seguir, que o caminho da pesquisa vai sendo construído de acordo com a vivência da experiência.

As etapas iniciais da pesquisa instituíram um universo bastante conflitivo, para mim e para os sujeitos participantes. Do contexto, emergiram tensões relacionadas à dificuldade de problematizar um tema - chegando até configurar-se um problema a tal problematização - resistências em abandonar as aulas tradicionais que tanto criticavam e dificuldades em superar as amarras de uma avaliação pontual e finalística, limitando-se a exercícios fechados de memorização e fixação (US11. Abreu,2016).

Cabe aqui uma articulação da unidade com o pensamento de Guedes e Ribeiro (2019) quando escrevem que os caminhos vão se delineando durante a experiência da pesquisa e que nesse movimento surgem inquietações, questionamentos, incertezas, que passam a ser compreendidos. Guedes e Ribeiro (2019) mostram que o caminho da pesquisa é sem rumo e sem certeza e que, a partir da experiência, é possível construir significados no processo investigativo.

Uma pesquisa que busca escutar e prestar atenção como forma de estar presente, de colocar em questão o próprio caminho percorrido e a percorrer, uma abertura a que tão facilmente escapa: o riso, o olhar apaixonado, o corpo inquieto, o sussurro insistente, os bilhetes trocados, a palavra não dita, o silêncio que grita, a palavra dissimulada, o abraço que acolhe, a brincadeira que aproxima, o sentimento que afasta, a merenda compartilhada, o desejo inexpresso, a força interrompida... (p.29).

Deste modo, apostamos na experiência de pesquisa como construtora de significados, conhecimento, aprendizagem, inquietações e questionamentos. Sob essa perspectiva, a metodologia necessita permitir a abertura de diálogo entre a teoria e a vivência do pesquisador e dos sujeitos colaboradores. $\mathrm{O}$ fragmento a seguir remete ao processo de abertura para construção de significados a partir das experiências vividas na formação inicial.

O ensino de ciências interdisciplinar ainda é incomum em nossas escolas e também não são frequentes as oportunidades de formação do professor com esta perspectiva. No clube de ciências da UFPA, estagiários de diferentes licenciaturas trabalham em equipes multidisciplinares e têm oportunidades de realizar um ensino interdisciplinar. Me interessei por conhecer a contribuição desse estágio para o trabalho pedagógico posterior do egresso, na escola (US12. Ribeiro, 2017). 
Como diz a unidade, a presença do pesquisador está em compreender o papel do estágio numa perspectiva interdisciplinar. Há um interesse em conhecer a contribuição do estágio, mas parece que o papel do pesquisador é de observar o lugar da pesquisa, e assim buscar compreender como que os sujeitos significam a experiência de estágio durante sua formação inicial. Nessa dissertação, a intenção é compreender o quanto a experiência do estágio, vivido na sala de aula, tem um significado na formação inicial dos sujeitos colaboradores. Trata-se de uma "pesquisa-escrita que se ocupa dos restos, rastros, marcas e minúcias, que nasce da inquietude e nela se renova" (Guedes e Ribeiro, 2019, p.31). Nela, mostramos que cada experiência, quando vivida abertamente pelo sujeito, constrói algum significado. Vemos, a seguir, um excerto que mostra a intenção de perceber o significado das experiências vividas pelos sujeitos:

O presente estudo tem como objetivo de pesquisa os saberes e as experiências das crianças na Educação em Ciências, reconhecendo-as como atores sociais competentes, levando em consideração suas culturas infantis (US19. Mululo, 2017).

O pesquisador mostra a intenção da pesquisa quando diz que o objetivo são os saberes e as experiências das crianças na Educação em Ciências. Ele constrói significados nas vozes das crianças utilizando diário de campo, gravadores e câmeras, e nesse movimento vive a experiência. Ao compreender como as crianças viveram a experiência, este sujeito constrói os caminhos da sua pesquisa. Guedes e Ribeiro (2019) corroboram com a ideia;

[...]a indagação. Compreendemo-la, aqui, como uma força capaz de nos sacar de nossos lugares tão aconchegantemente conhecidos, de abalar nossos alicerces cognitivos. E indagação não apenas do que estamos investigando, observando, dos "dados" de pesquisa, mas também - e principalmente - da própria ação de investigar, dos próprios caminhos trilhados (p.35-36).

Assim, destacamos a pesquisa que "envolve processos singulares de formação. Processos educativos e de formação entendidos como processos de construção de subjetividade (US10. Pereira, 2015)", pois mostra o quanto o caminhar de uma experiência constrói significados.

O fragmento refere-se ao resumo da dissertação trazido na categoria anterior, quando buscamos mostrar as diferenças de experiências e também a relação do pesquisador com a pesquisa partindo da experiência. Aqui ela se faz presente, pois revela os significados que o pesquisador construiu em sua experiência formativa. Nessa 
Edição Especial: I SSAPEC - Simpósio Sul-Americano de Pesquisa em Ensino de Ciências

ISSN: 2595- $4520 \quad$ Vol. 4, n. 3. 2021

dissertação, o pesquisador busca compreender sua experiência de formação a partir da leitura de um livro, e assim remete aos significados a partir da experiência vivida em sua trajetória acadêmica.

O movimento de pesquisar tornou-se um caminho a ser vivido na perspectiva da experiência, pois observamos nas unidades que esse caminhar deve ser escutado, escrito e compreendido pelo pesquisador e sujeitos colaboradores para que a vivência seja significativa. O pesquisador está aberto a viver a experiência em pesquisar, mesmo que não seja o sujeito pesquisado. Uma pesquisa outra que, ao buscar compreender a experiência do outro e assim a construção do conhecimento, vai se tornando mais intensa e de forma mais clara em seu caminhar da pesquisa.

Seguimos para a categoria final, que busca perceber a experiência construída nas relações entre o pesquisador e sujeitos colaboradores no processo investigativo.

\subsection{A EXPERIÊNCIA NAS RELAÇÕES ENTRE O PESQUISADOR E OS SUJEITOS COLABORADORES}

A presente categoria emergiu com a intenção de perceber como a relação entre o pesquisador e os sujeitos colaboradores da investigação é construída, visto que as dissertações analisadas destacam a experiência como caminho para a investigação. Assim, questionamos em que momento essa relação pesquisador e sujeitos colaboradores se constitui e qual a importância da construção dessas relações. Clandinin e Connelly (2015) apontam essa relação, pesquisador-participante, como frágil, pois em cada passo que é dado no campo da pesquisa ela está sujeita a ser negociada novamente. A unidade seguinte mostra esse movimento de pesquisa e relação do pesquisador e sujeitos colaboradores.

Os resultados nos mostram que exposições e demonstrações que possibilitam ao aluno a interação entre ele e o monitor associando os saberes práticos e teóricos, despertam a curiosidade dos alunos (US3. Otofuji, 2013).

A relação do pesquisador com os sujeitos colaboradores é percebida de forma que o caminhar da pesquisa é delineado pelos próprios colaboradores. E essa relação se faz necessária para compreender como que os sujeitos colaboradores compreendem a experiência, nesse caso as curiosidades que surgiam nos sujeitos durante a experiência 
vivida. Clandinin e Connelly (2015, p.110) afirmam que "os propósitos e aquilo que uma pessoa está explorando e considera enigmático mudam no desenrolar da pesquisa". A relação do pesquisador com os sujeitos colaboradores, mesmo que não intimamente, existe quando o pesquisador adentra a experiência dos sujeitos em busca de compreender o fenômeno investigado. $\mathrm{Na}$ unidade seguinte, novamente, o que se interpreta é a percepção e abertura do pesquisador quanto às experiências vividas pelos sujeitos em sua pesquisa, a singularidade das experiências de cada estagiário, como podemos observar.

Apesar da singularidade das experiências de cada estagiário, egresso do CCIUFPA, os resultados mostraram que os professores consideraram que o estágio no clube de ciências ampliou seus conhecimentos sobre interdisciplinaridade, ensinou-os a enfrentar e superar dificuldades para realizar projetos interdisciplinares, favoreceu o planejamento $e$ a valorização das atividades em equipe, a motivação dos sócios mirins, a contextualização dos conteúdos e o diálogo em sala de aula (US12. Ribeiro, 2017).

A interrelação entre as experiências é o destaque da unidade, a atenção às experiências dos sujeitos são percebidas pelo pesquisador, que consegue fazer relação entre ambas pelo envolvimento e dedicação com a pesquisa. Clandinin e Connelly (2015) abordam sobre a construção da intimidade entre pesquisador e participante:

[...] o pesquisador precisa se inserir nesta por um bom tempo, prestar atenção e questionar as situações para compreender os eventos e histórias, as muitas narrativas que se inter-relacionam a cada instante e que apontam, frente a seu olhar ainda inexperiente, caminhos na compreensão de mistérios (p.115).

A forma de dar expressão à experiência dos colaboradores é mencionada por Guedes e Ribeiro (2019, p.41), a decisão é do pesquisador, "isto porque uma pesquisa em primeira pessoa, com assinatura e nome próprios, há que ter face, cheiro, presença". Na próxima unidade, evidenciaremos a maneira que o pesquisador se coloca na pesquisa e sua grande responsabilidade em promover espaços de escuta às vozes dos sujeitos/colaboradores, oportunizando que os mesmos sejam vistos e reconhecidos. Na pesquisa, as experiências compartilhadas são notadas no caminhar do processo, como podemos observar na unidade abaixo:

Diante da análise e do estudo realizado, pode-se compreender que a constituição do professor-pesquisador é fundamentada pelo trabalho coletivo, por espaços de diálogo e escrita, na interação com a escola e na compreensão de aprendizagem e pesquisa a partir da prática (US2. Calixto, 2013). 
Nese resumo, percebemos a importância do trabalho coletivo no processo investigativo, pois o mesmo torna a experiência significativa para o pesquisador e seus colaboradores. Guedes e Ribeiro (2019) dialogam sobre viver a experiência do pesquisar quando dizem que:

Trata-se de um modo de se portar e de se colocar na pesquisa que deita a atenção sobre detalhes, curvas, ocos, ausências, linhas abertas, resíduos... Em outras palavras uma pesquisa que mantém os sentidos afiados: olfato, tato, paladar, audição e visão para buscar tornar visível o que está, até então, invisível, silenciado, esquecido. (p.40)

No excerto abaixo, há também a reflexão sobre a relação do pesquisador com seus colaboradores:

Os resultados mostram que os professores-estagiários (res)significam suas experiências formativas ao ensinar Ciências em um processo investigativo que exclui visões deformadas e ingênuas propagadas pela escola formal e pelos meios de comunicação e informação. Ao vivenciar tal processo eu também (res)significo minha visão de Ciência e minha formação em um movimento de compreender tais compreensões. Elas me tocam, me modificam, me movem, me tornam quem eu sou, o que me faz refletir que tais análises acerca das compreensões podem contribuir na formação de professores os possibilitando de fazer Ciência ao ensinarem Ciências para seus alunos (US8. Cajueiro, 2017).

Percebe-se, portanto, que o caminhar da pesquisa se constrói pela relação do pesquisador, colaboradores e vivência, culminando no momento em que ambos vivem a experiência e se permitem construir significados. Guedes e Ribeiro (2019, p.20) “...acreditamos na mobilidade, no movimento e no estar com outros, transformando-se com outros como uma força vital que nos força a seguir pensando(-nos), estranhando(nos), fazendo(-nos) outros". Dialogando com os autores acima, é necessário no ato da pesquisa ficar atento e aberto ao caminhar, ao meio, dando abertura e atenção a todos os movimentos, nunca esperar chegar ao fim sem desfrutar do caminho que percorreu.

É fundamental permitir-se viver a experiência, tanto dos colaboradores quanto do pesquisador: experiência essa que favorece um pesquisar aberto a novos rumos, sem a busca de respostas, e nem uma linha única a percorrer, e sim uma abertura para viver o inesperado na pesquisa.

Interessa-nos as possibilidades abertas pelos processos, as experimentações. Experiências singulares e singularizantes de formação, provocando uma abertura para outras possibilidades, outros modos de agir, sentir, pensar (US10. Pereira, 2015). 
Edição Especial: I SSAPEC - Simpósio Sul-Americano de Pesquisa em Ensino de Ciências ISSN: 2595- $4520 \quad$ Vol. 4, n. 3. 2021

A relação e a abertura em compartilhar as experiências vividas faz com que esse caminhar torne o foco da pesquisa, o desafio de tomar as experiências dos sujeitos como aquilo que força o pensamento (Guedes e Ribeiro, 2019, p.32). Assim, o fragmento mostra uma relação entre pesquisador, colaborador e experiência, abrindo para outras possibilidades, outros rumos no decorrer da investigação.

Por fim, essa categoria teve a intenção de perceber a relação entre os sujeitos colaboradores e o pesquisador na pesquisa, como também os caminhos do pesquisar vivenciados por ambos. Através das unidades e dos autores trazidos para dialogar com esse movimento de permitir-se viver a experiência que é destaque nessa categoria. Também nesse movimento de compreender os resumos de dissertações, destacamos o "respeito" e a "voz" que os participantes têm durante a pesquisa.

\section{CONSIDERAÇÕES FINAIS}

A intenção desse movimento de análise foi aprofundar as compreensões relacionadas à palavra experiência presente nos resumos das dissertações na área da Educação em Ciências. Buscamos, nesse processo, aproveitar e desfrutar do estudo bibliográfico, sem buscar um determinado lugar e resultado, e sim perceber como cada pesquisa se mostra em relação à experiência.

Cada categoria final que emergiu nessa análise é movida pelos sentimentos, olhares e inquietações a partir de uma leitura atenta a cada resumo. Partimos da abordagem fenomenológica e hermenêutica por permitir perceber como se mostra a experiência vivida naquele momento de pesquisa, tanto do pesquisador quanto dos sujeitos.

As três categorias emergentes possibilitaram compreender a palavra experiência nas pesquisas em Educação em Ciências os sentidos e significados construídos quando adentramos a viver experiências e a importância das relações estabelecidas entre o pesquisador e os sujeitos colaboradores. Nesse movimento, percebemos a presença do pesquisador, o lugar da pesquisa, a relação do pesquisador com a pesquisa em si, os sujeitos colaboradores em que cada experiência narrada na pesquisa se torna única para cada sujeito que vive aquele momento. 
Assim, argumentamos o emergente nesse estudo sobre a maneira de pesquisar, a qual, muitas vezes, obedece às exigências centradas em normas e modelos, fazendo com que o pesquisador e/ou sujeitos percam suas características de escrita, assim não se reconhecendo como autores no processo investigativo. Quando nos permitimos viver o caminho da experiência na pesquisa, há um encontro das percepções, sentimentos, olhares e transformações.

Aprender, pensar e transformar são palavras que o pesquisador e sujeitos precisam e percebem durante o experienciar de suas pesquisas. Como conclusão dessa análise, o minúsculo percebido só foi alcançado pelo foco não estar no resultado da pesquisa, mas se atentar aos caminhos que ela percorreu. Sendo assim, conclui-se que, na pesquisa importa mais o movimento do pesquisar, os caminhos, do que a chegada. É permitir-se viver o encontro com a experiência, viver e contemplar os caminhos desse mundo que é pesquisar.

\section{REFERÊNCIAS}

AMATUZZI, M. M. (2007). Experiência: um termo chave para a Psicologia. Memorandum: Memória E História Em Psicologia, 13, 8-15. Recuperado de https://periodicos.ufmg.br/index.php/memorandum/article/view/6699

CARLESSO, D.; TOMAZETTI, E.M. As condições de (im)possibilidades da experiência em John Dewey e Jorge Larrosa: Algumas aproximações. Revista Reflexão e Ação, Santa Cruz do Sul, v.19, n.2, p.75-97, jul./dez. 2011.

CLANDININ, J.; CONNELlY, M. Pesquisa Narrativa: experiência e história de pesquisa qualitativa. Tradução: Grupo de Pesquisa Narrativa e Educação de Professores ILEEL/UFU. $2^{\circ}$ edição rev. Uberlândia: Editora UFU, 2015.

GADAMER, HANS GEORG.1900. Verdades e métodos/Hans Georg Gadamer: tradução de Flávio Paulo Meurer- Petrópolis, RJ:Vozes,1997.

GUEDES, A.O; RIBEIRO, T. Pesquisa, alteridade e experiência: metodologias minúsculas. Rio de Janeiro: Ayvu, 2019. 304p.

GULLICH, R.I.S. O livro didático, o professor e o ensino de ciências: um processo de investigação-formação-ação. Tese de Doutorado. Universidade Regional do Noroeste do Estado do Rio Grande do Sul (Campus Ijuí). 2012. 263p. 
LARROSA, J. Notas sobre a experiência e o saber de experiência. Tradução de João Wanderley Geraldi. Universidade Estadual de Campinas, Departamento de Linguística. Revista Brasileira de Educação. n.19. jan/fev/mar/abr. 2002.

MORAES, R.; GALIAZZI, M.C. Análise textual discursiva. 3.ed.revista e ampliada. Ijuí: Editora Unijuí, 2016.

RIBEIRO, T.; SOUZA, R.; SAMPAIO, C.S. Conversa como metodologia de pesquisa: por que não?. Rio de Janeiro: Ayvu, 2018. 216p.

SOUSA, R.S. A hermenêutica filosófica no horizonte da Educação em Química: o professor de Química como tradutor-intérprete de uma tradição de linguagem. Tese Doutorado. Universidade Federal do Rio Grande-Furg. 2016. 100p.

SOUSA, R.S; GALIAZZI, M.C. Experiências Estéticas na Pesquisa em Educação Química: Emergências Investigativas na Formação de Professores de Química em uma Comunidade Aprendente. Revista de Educação, Ciência e Matemática. V.9. n.2. maio/agosto. 2019.

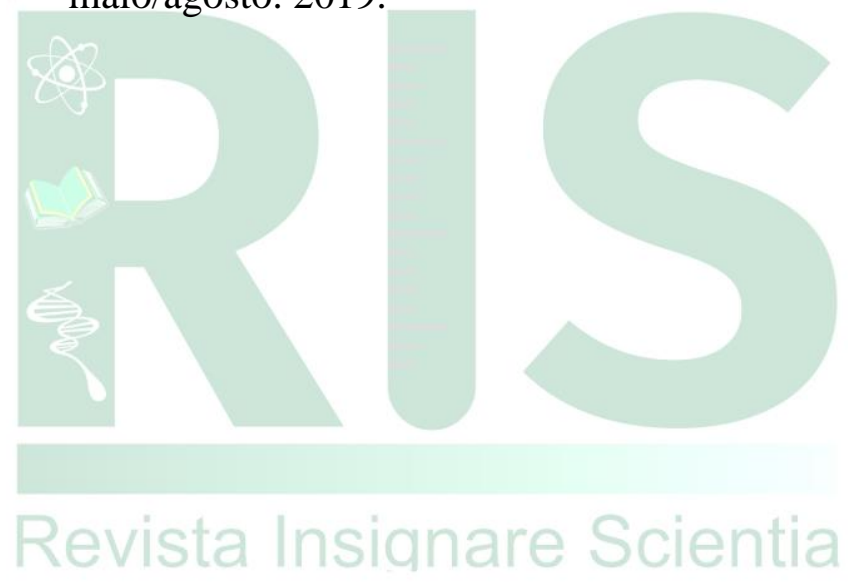

